\title{
Investigating the Status of Factors Leading to Job Stress According to ILO Checkpoint in Hamadan University of Medical
} Sciences

\section{Mohammad Babamiri (PhD) ${ }^{1}$, Rashid Heydarimoghadam (PhD)², Majid Motamedzade $(\mathrm{PhD})^{3}$, Ziba Abdi (MSc) ${ }^{4, *}$, Hamid Saeidnia (MSc) ${ }^{\mathbf{5}}$}

${ }^{1}$ Department of Ergonomics, Research Center for Health Sciences, School of Public Health, Hamadan University of Medical Sciences, Hamadan, Iran

${ }^{2}$ Department of Ergonomics, School of Public Health, Hamadan University of Medical Sciences, Hamadan, Iran

${ }^{3}$ Department of Ergonomics, School of Public Health, Hamadan University of Medical Sciences, Hamadan, Iran

${ }^{4}$ MA of Ergonomics, Department of Ergonomics, School of Public Health, Hamadan University of Medical Sciences, Hamadan, Iran

${ }^{5}$ MA of Ergonomics, Department of Ergonomics, School of Public Health, Hamadan University of Medical Sciences, Hamadan, Iran

* Corresponding Author: Ziba Abdi, MA of Ergonomics, Department of Ergonomics, School of Public Health, Hamadan University of Medical Sciences, Hamadan, Iran.Email: z.abdi69@gmail.com

\section{Abstract}

Received: $31 / 12 / 2017$

Accepted: 08/04/2018

\section{How to Cite this Article:}

Babamiri M, Heydarimoghadam R, Motamedzade M, Abdi Z, Saeidnia $H$. Investigating the Status of Factors Leading to job Stress According to ILO Checkpoint in Hamadan University of Medical Sciences. Pajouhan Scientific Journal. 2018; 17(1): 9-15. DOI: 10.29252/psj.17.1.9
Background and Objective: With respect to the importance of job stress in causing diseases and disorders among workers, the purpose of this study was to examine the staff's opinion on the level of implementation and prioritization of the most important stressors among Hamadan University of Medical Sciences (UMSHA) staff.

Materials and Methods: The present study was quantitative and descriptive in design. The research population was UMSHA staff, that among whom 250 were selected by simple random sampling method. Research tool was ILO Stress prevention checkpoints. Data analysis was done by SPSS 18.0 software (SPSS, Chicago, IL, USA).

Results: The results showed that staff opinion about the priority of intervention about the causes of stress are as follows: leadership and justice at work (32\%), job security (32\%), job control (29\%), job demands (26\%) and recognition (22\%). Also staff opinion about the stressful factors that are not running are as follows: leadership and justice at work (52\%), job demands (57\%), job control (53\%), social support (57\%), physical environment (62\%), work-life balance and working time $(60 \%)$, recognition at work (58\%), protection from offensive behavior $(58 \%)$, Information and communication (59\%).

Conclusion: According to the results of this study, factors related to leadership and justice at work, job control, job demands, job security and recognition at work are main factors that managers should pay attention to them to reduce job stress.

Keywords: Job Stress; Prevention; ILO

Copyright (C) 2018 Pajouhan Scientific Journal. This is an open-access article distributed under the terms of the Creative Commons Attribution-NonCommercial 4.0 International License (http://creativecommons.org/licenses/by-nc/4.0/) which permits copy and redistribute the material just in noncommercial usages, provided the original work is properly cite. 
بررسى وضعيت عوامل منجر به استرس شغلى بر اساس جـ يوينت سازمان جهانى كار در

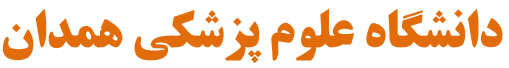

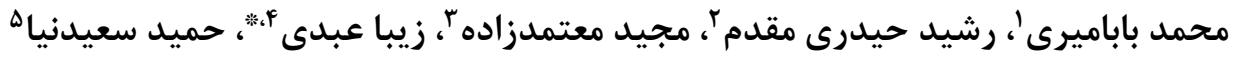 \\ ' مركز تحقيقات علوم بهداشتى و گروه اركونومى، دانشكده بهداشت، دانشگاه علوم يزشكى همدان، همدان، ايران

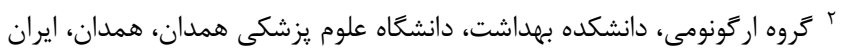

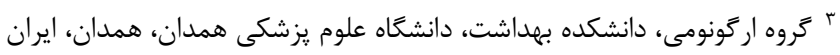

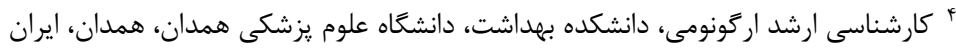

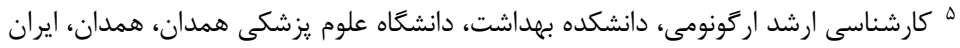 \\ * نويسنده مسئول: زيبا عبدى، كارشناسى ارشد ارگَونومى، دانشكده بهداشت، دانشًاه علوم يزشكى همدان، همدان، ايران. \\ ايميل: z.abdi69@gmail.com
}

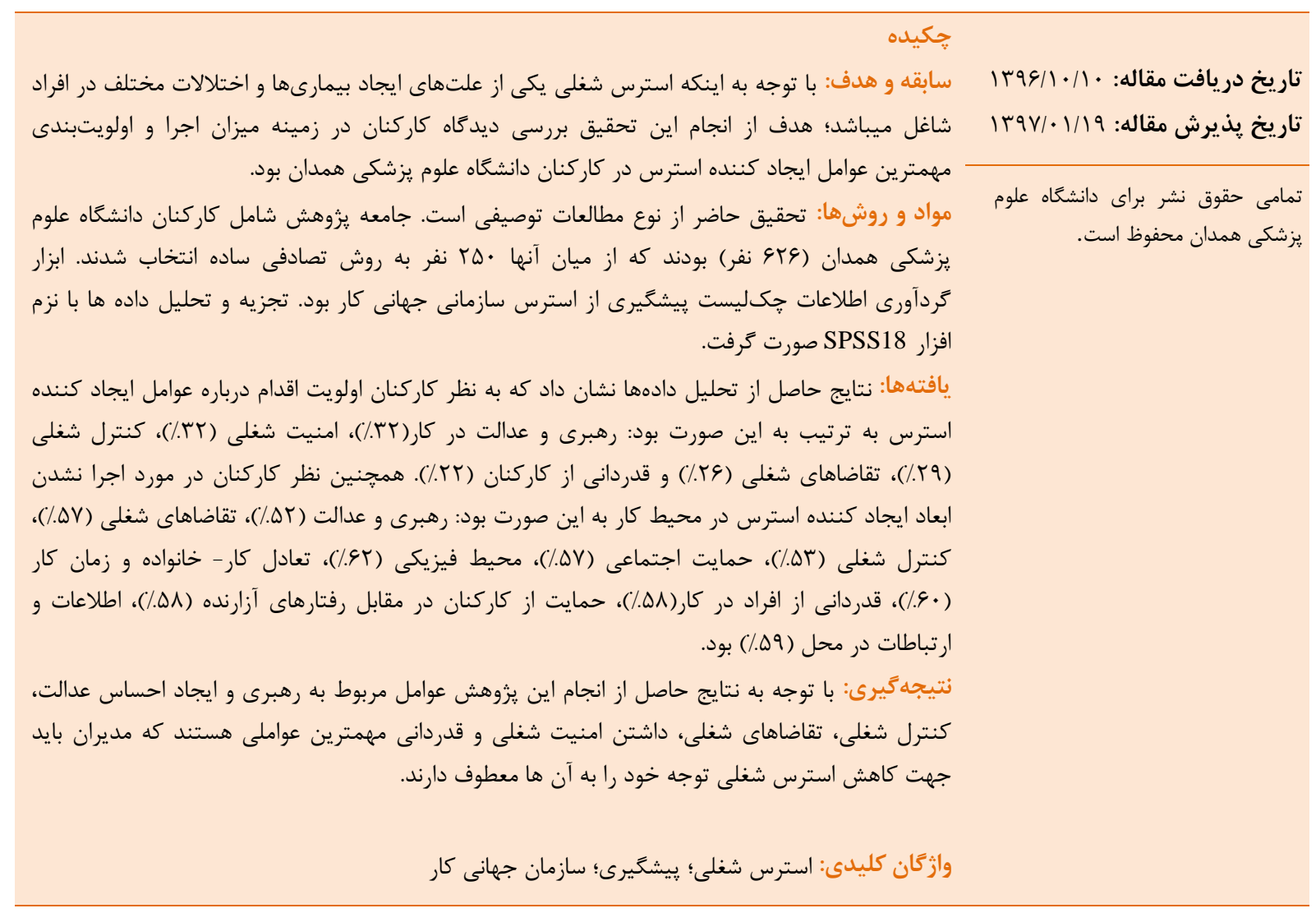

مقلهمه

بيمارىهاى جسمانى و روانى مرتبط است كه دامنه آن ها بسيار متنوع است مانند: سردرد تنشى، كمر درد، گردن درد، گراستريت،

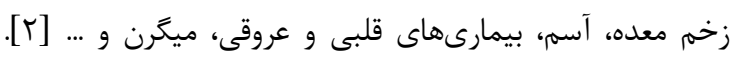

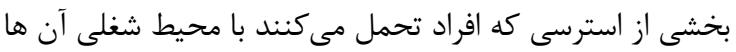
درارتباط است. موسسه ملى ايمنى و بهداشت استى حرفهاى آمريكا

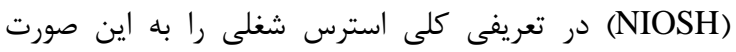
تعريف كرده است؛ استرس شغلى واكنشهاى فيزيكى و جسمانى
با رشد اقتصاد جهانى، افزايش رقابت، تغيير روابط بين

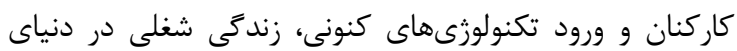

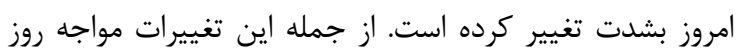
افزون كاركنان با استرس در محيط كار است. سازمان بهداشت

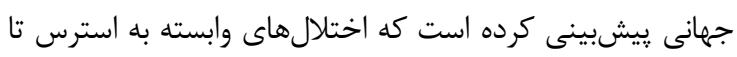

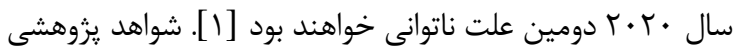
قوى وجود دارند كه نشان مىدهند استرس با تعداد زيادى از 
بازشناسى به عنوان مهمترين عوامل استرس زا مشخص شدند

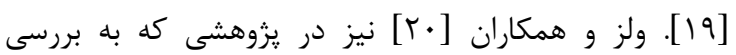

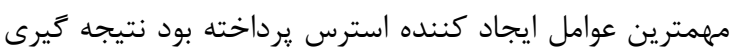

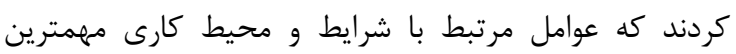

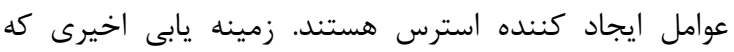
توسط سازمان جهانى كار (ILO) انجام شده نشان داده است است كه در مطالعه و كاهش استرس در كار، نكات معمول و قابل

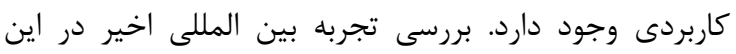

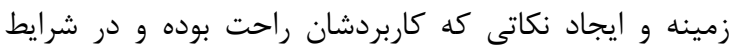

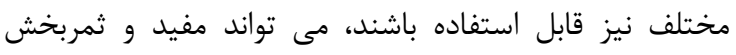

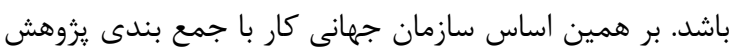

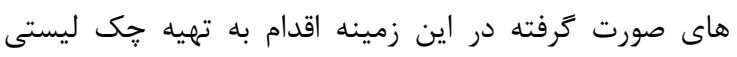

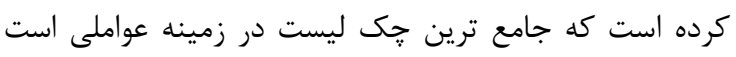
كه به استرس شغلى منجر مى شى استد. نكته مهاتم در زمينه اين

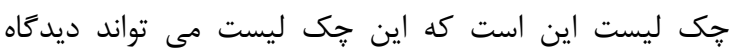

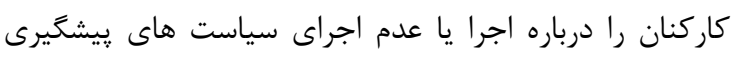

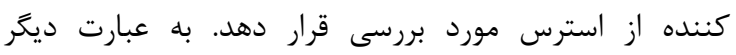

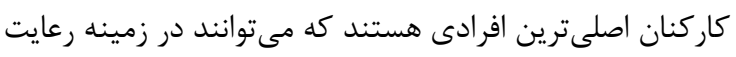
اين اصول در محيط كارى خود نظر بدهند. بررسى و مشخص

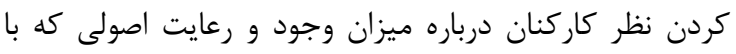
استرس شغلى در ارتباط هستند در بهينهسازى شرايط محل درد

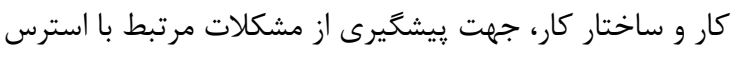

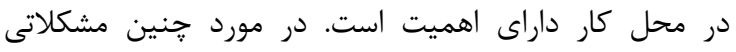

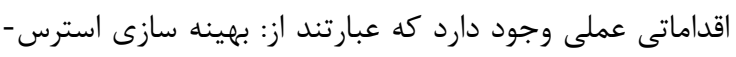
زاها در كار، در خانواده و در جامعله، افزايش توانايى مقابله كردن در كاركنان و تقويت كردن سيستم هاى حمايت از كاركنان ونان.

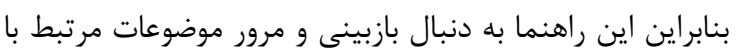

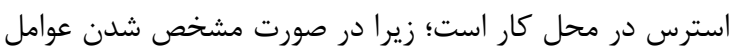

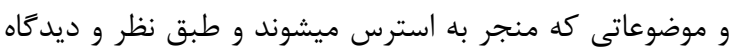

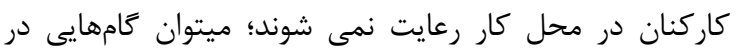

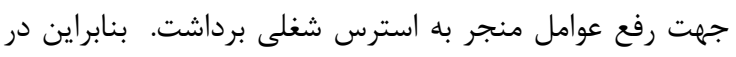

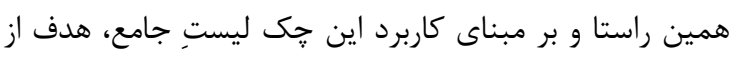

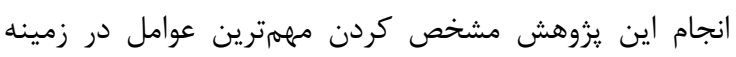

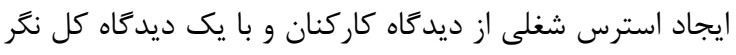

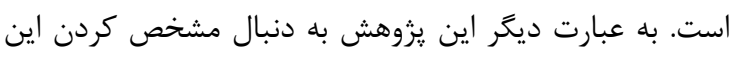

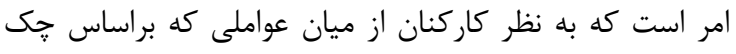
ليست ILO به استرس شغلى منجر ميشوند؛ كدام عوامل در

$$
\text { سازمان ملموس نيست و يا به اجرا در نمى آيد. }
$$

\section{مواد و روشها}

يزوهش حاضر از نوع مطالعات توصيفى مىباشد. جامعه

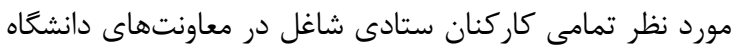

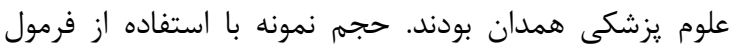

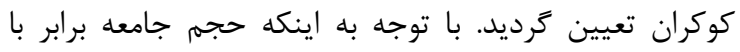

خطرناكى است كه در صورت عدم تطابق بين نيازمندىهاى شغل

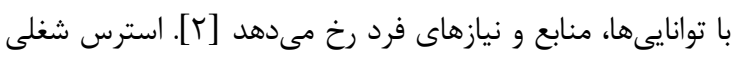

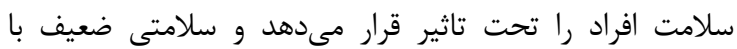

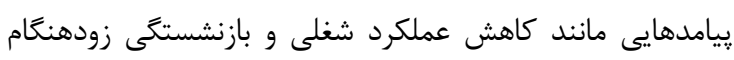

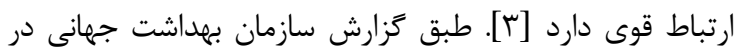

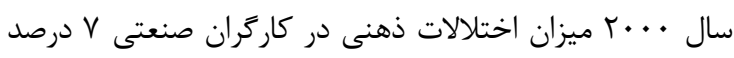

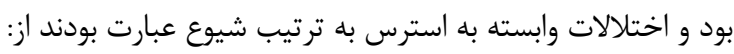

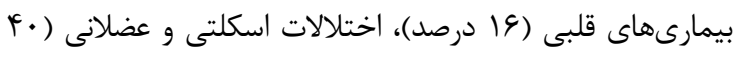

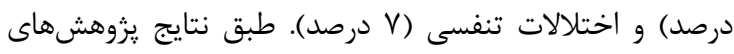

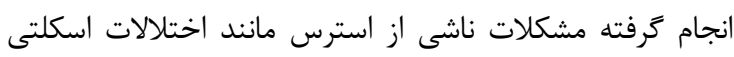

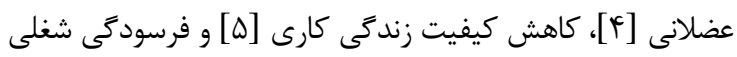

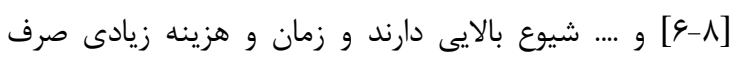

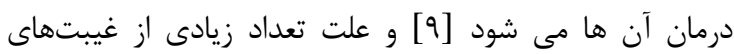

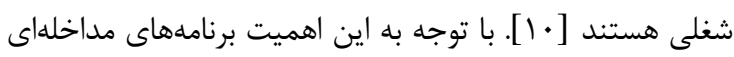
مختلفى نيز در جهت مديريت استرس شغلى كاركنان طراحى

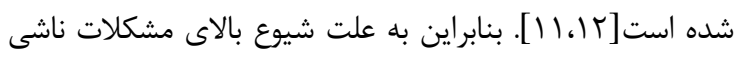

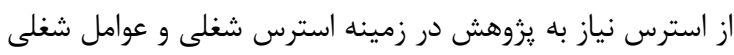

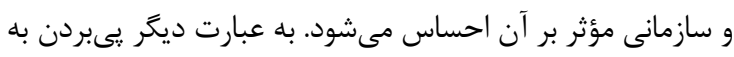
ميشبينى كنندهاى استرس شغلى در موقعيتهاى شغلى داراى اهميت است. علاوه بر مساله بيان شده نكته قابل ذكر اين است كه

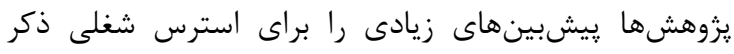

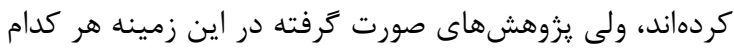

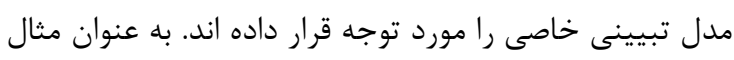
يزوهشها بر روى متغيرهاى دو مدل بسيار تأكيد كردهاند:

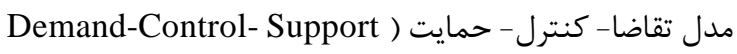
Effort-Reward و مدل عدم توازن تلاش - پياداش (Model

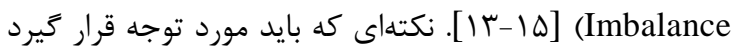
اين است كه آنجه كه در نتيجه يروهش هاى انجام شده منجر به

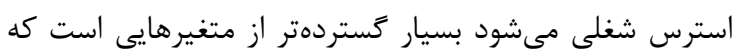

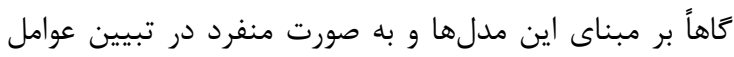

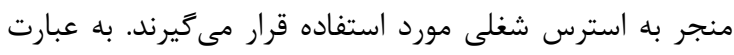

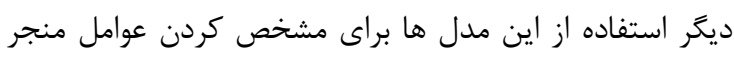

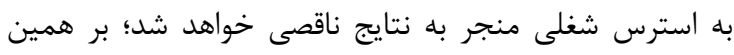

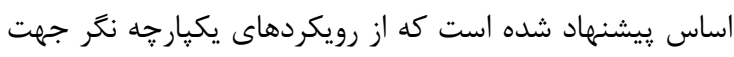
بررسى استرس شغلى استفاده گردد [19]. جهت دستيابى به اين هدف در كشورهاى مختلف مطالعات الثناده

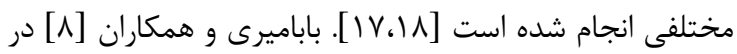

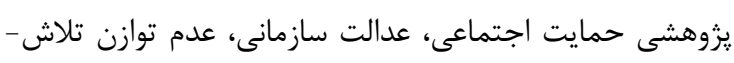

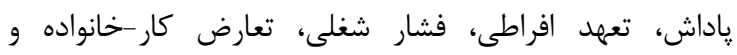

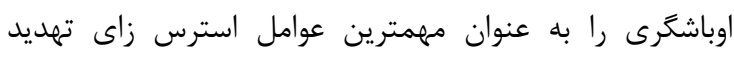

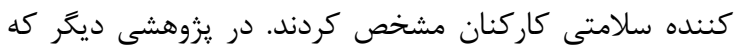

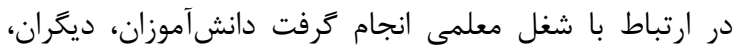

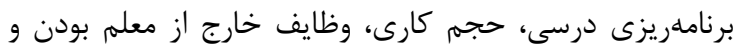


/VA • محاسبه گرديد. از آنجايى كه در يروهش حاضر هدف

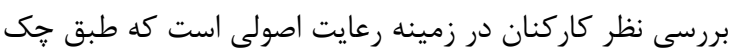

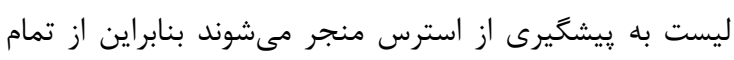

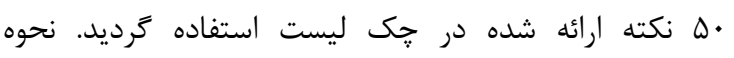
קاسخكَويى به اين جك ليست به اين صورت است كه اتر فرد

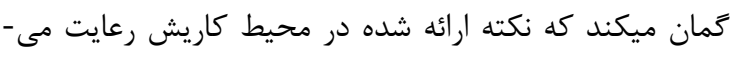

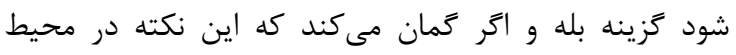

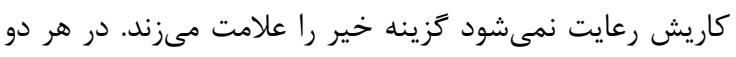

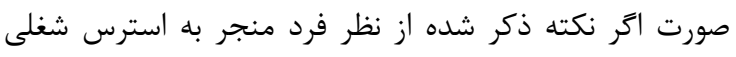

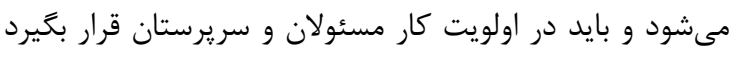

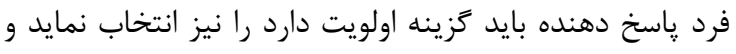
در صورتى كه نكته ذكر شده از نظر فرد در محيط كارى باش از از

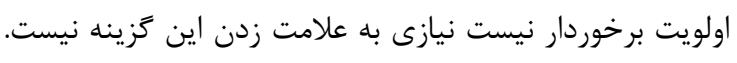

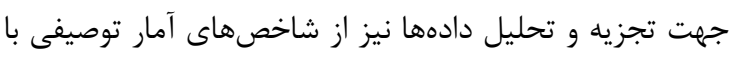

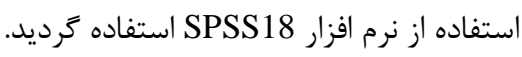

1. إِفته

•

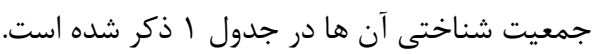
ميانكين سن افراد شركت كننده در يزوهش

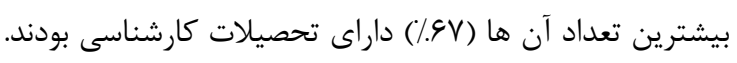

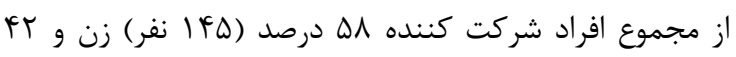

$$
\text { درصد (ه • ا نفر ) نيز مرد بودند. }
$$

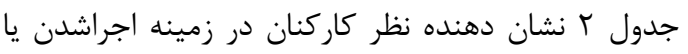

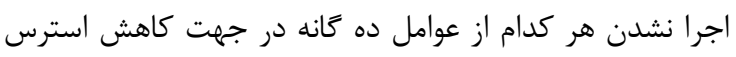

GT\& نفر است تعداد اعضاى نمونه با استفاده از فرمول

$$
n=\frac{\frac{z^{2} p q}{d^{2}}}{1+\frac{1}{N}\left(\frac{z^{2} p q}{d^{2}}-1\right)}
$$

برابر با یrr نفر محاسبه گرديد. طبق جدول مورگان نيز براى

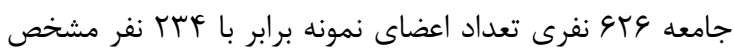

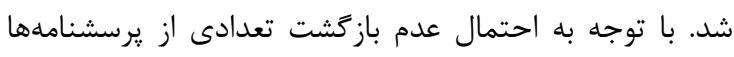
•

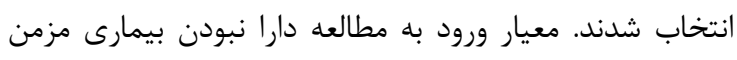
جسمانى يا روانى بود كه به صورت يك سوال كلى از رئل ياسخ

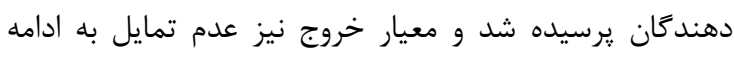

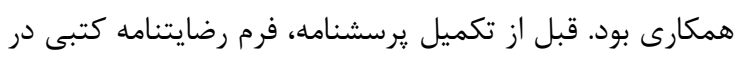

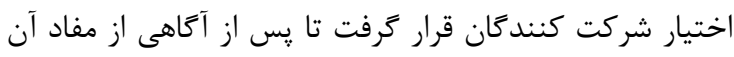

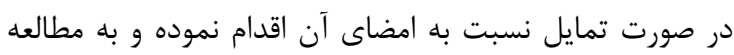

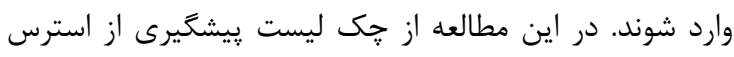

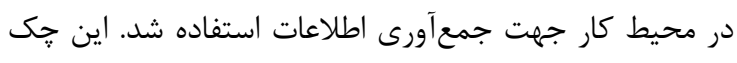

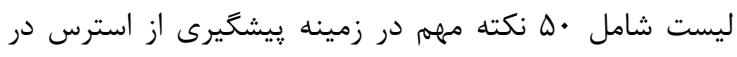

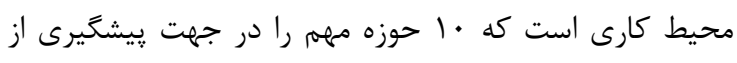

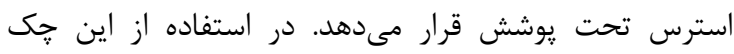

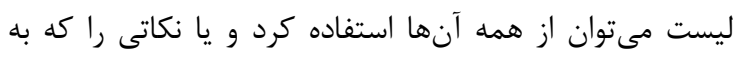

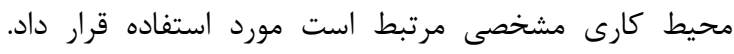

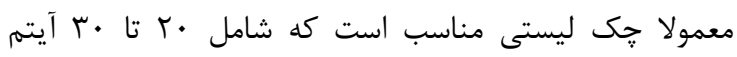

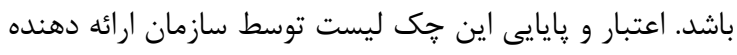

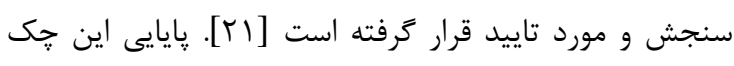

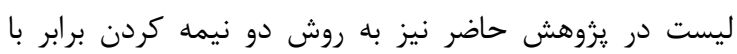

جدول (: متغيرهاى دموكرافيك شركت كنندكان

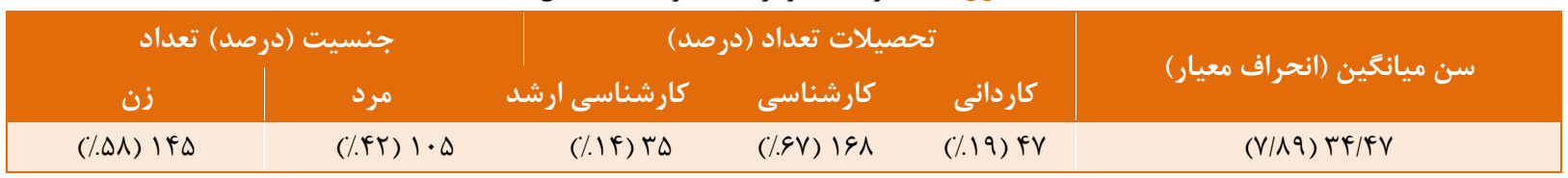

\begin{tabular}{|c|c|c|}
\hline تعداد (درصدا نمىشود & تعداد (درصد) اجىشود & 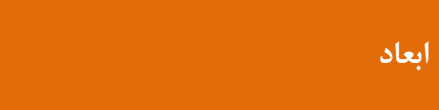 \\
\hline$(\Delta T) F \Delta F$ & $(F \wedge) F T$. & رهبرى و عدالت \\
\hline$(\Delta V) \& \wedge$. & (FT)KG. & تقاضاهاى شغلى \\
\hline$(\Delta r) F \Delta G$ & $(F V) F i r$ & 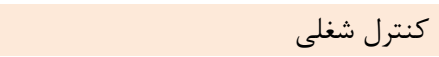 \\
\hline$(\Delta V) \& \wedge q$ & (FT)rVH & 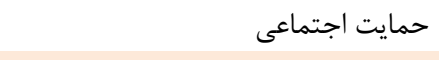 \\
\hline (GT)QHG & 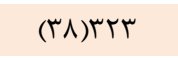 & محيط فيزيكى \\
\hline$(/ .9 \cdot) D F F$ & $(/ . \uparrow \cdot) \mu \varphi q$ & تعادل كار - خانواده و زمان كار \\
\hline$(/ . \Delta \Lambda) \& q \Delta$ & $(/ . F T) H G V$ & قدردانى از افراد \\
\hline$(/ . \Delta \Lambda) \& q 1$ & $(/$ FTIMDI & حمايت از كاركنان در مقابل رفتار آزارنده \\
\hline$(/ . \Delta \cdot) r \cdot r$ & $(/ . \Delta \cdot)|f| \cdot$ & امنيت شغلى \\
\hline$(/ .09) 499$ & $(/ .41) r<q$ & اطلاعات و ارتباطات در محل كار \\
\hline
\end{tabular}

جدول با: ميزان اجرا شدن سياستهاى كاهش دهنده استرس در زمينه ابعاد ده گانه از ديد 
نمودار ا نشان مىدهد كه به نظر كاركنان از بين عوامل

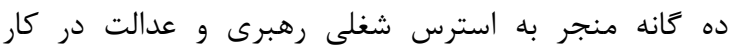

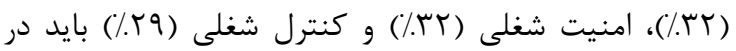
اولويت اقدامات لازم در جهت كاهش استرس قرار بخيرند.

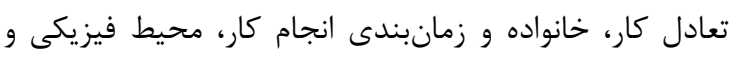

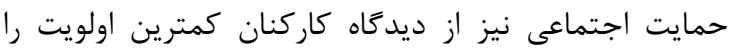

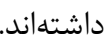

بر اساس نتايج جدول r از بين عوامل ده كانه ايجاد كننده

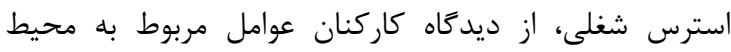

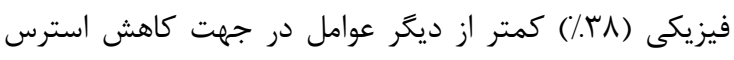

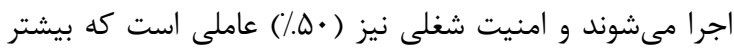
از ساير عوامل مورد توجه قرار مى خيرد.

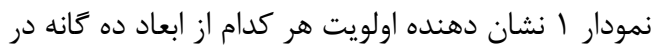
جهت كاهش استرس از ديدگاه كاركنان است.

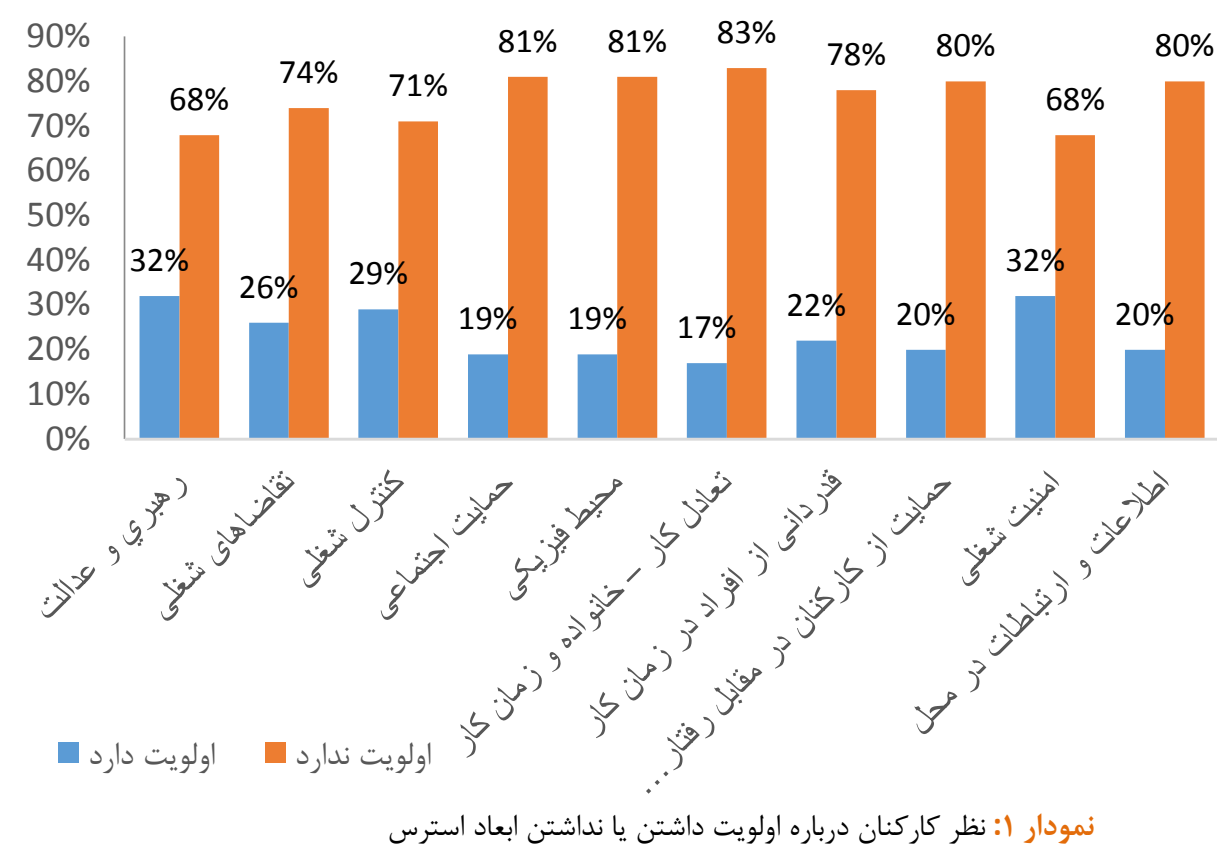

است [YI]]. براساس نظر مسلج كه براساس نظريههاى عدالت

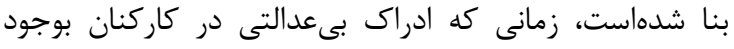

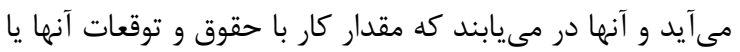
انتظار و توقع فرد با سنجش وى در در مقايسه با ديخران نامتناسب

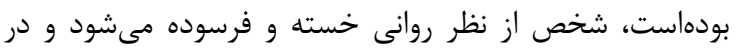

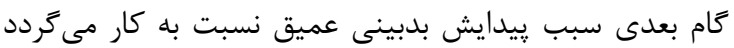

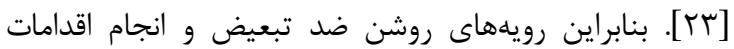

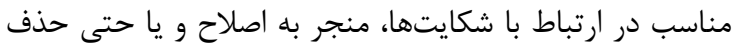

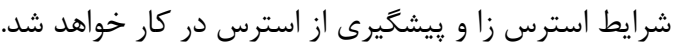

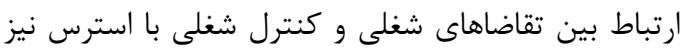

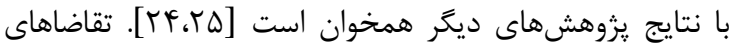

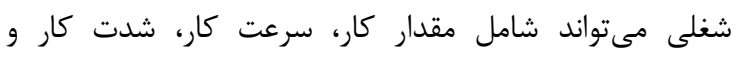
زمانبندى كار است. مشخص شدهاست كه تقاضاى شغلى زياد

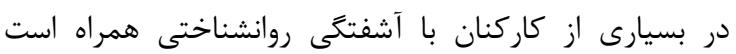

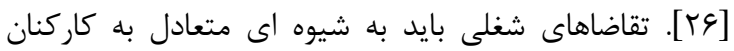

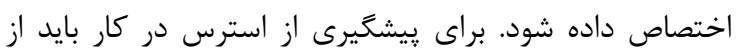
تقاضاهاى شغلى بيش از حد كه كاركنان خاص را تحت تاثير

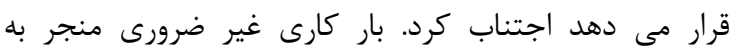
كرانبارى، فقدان زمان كافى براى انجام شغل يا اجبار بارى انجام
نتايج حاصل از تحليل دادهها اين يزروهش نشان داد كه به

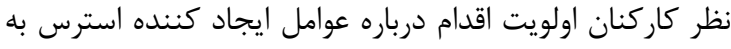
ترتيب به اين صورت است: رهبرى و عدالت در كار، امنيت

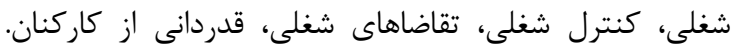

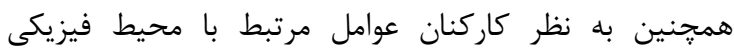

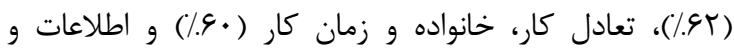

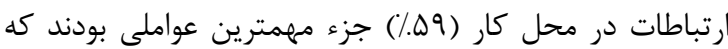

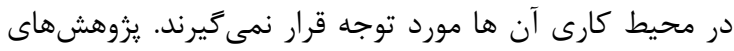

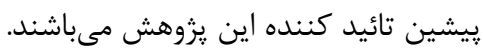

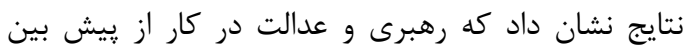

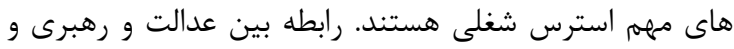
استرس در يزوهشهاى مشابه نيز مورد تاييد قرار كرفته است است فين

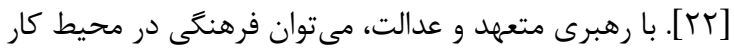

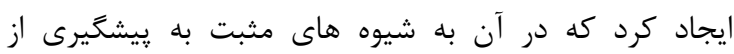

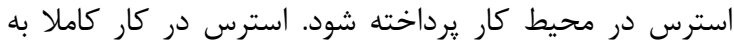

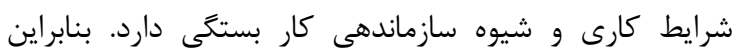
ييشگيرى از استرس در محل كار به سياستها و استراترىهاى

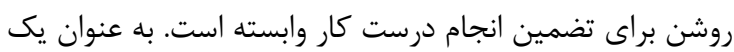

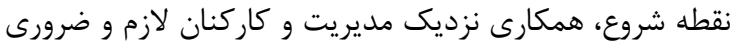


كارى خوب و روابط انسانى خوب را مشكل كرده و بر سلامت

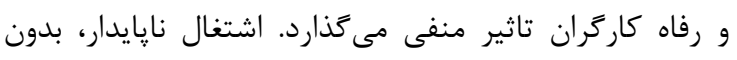
تضمين شرايط اشتغال مداوم و عادلانه، حفظ تعهد بـ به عملكرد

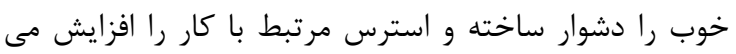

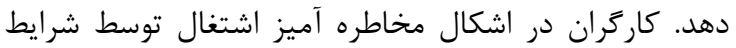
اجتماعى و اقتصادى تحت تاثير قرار گرفته و مستعد ابتلا به دراطيه استرس در محل كار هستند [YT).

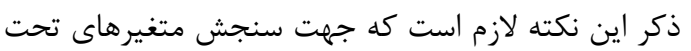

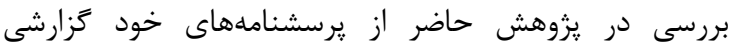

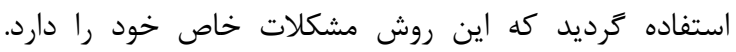

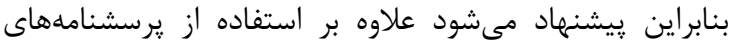

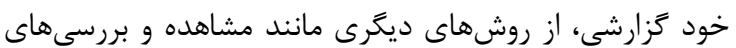
ميدانى نيز براى سنجش متغيرها استفاده شود. رون

\section{نتيجهن تيرى}

عوامل متعدد و مختلفى مى توانند باعث ايجاد استرس

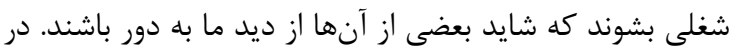

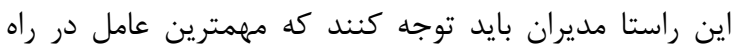
كاهش استرس؛ اين است كه سياستها و برنامه ها بر مسايلى مئى

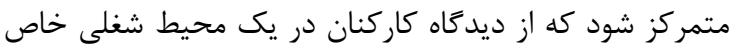

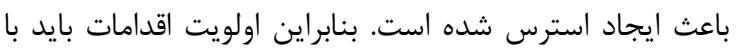

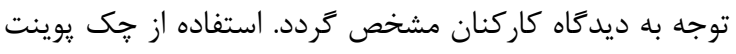

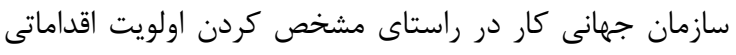

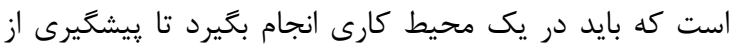
استرس شغلى را به عنوان ييامد به دنبال داشته باشد. بنابراين

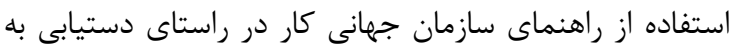
اين هدف توصيه مى گردد.

\section{تشع و قلمر فاذه}

اعضاى تيم يزوهش از معاونت تحقيقات و فناورى دانشكاه

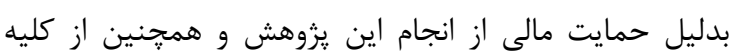
شركت كنندگان تشكر و قدردانى ميكنند.

تضاد منافع اين مطالعه براى نويسندَان هيجَّونه تضاد منافعى نداشته

\section{REFERENCES}

1. Gerber M, Pühse U. "Don't crack under pressure!"-Do leisure time physical activity and self-esteem moderate the relationship between school-based stress and psychosomatic complaints? Journal of psychosomatic research. 2008; 65(4):363-9.

2. Dollard M, Winefield HR, Winefield AH. Occupational stress in the service professions: CRC Press; 2003.

3. Mein G, Martikainen P, Stansfeld SA, Brunner EJ, Fuhrer $\mathrm{R}$, Marmot MG. Predictors of early retirement in British civil servants. Age and ageing. 2000;29(6):529-36.
سريع وظايف (به عنوان مثال از طريق ناديده گرفتن كيفيت كار و يا نداشتن استراحت) ميكردد. اگر توزيع كار نابرابر و ناعادلانه

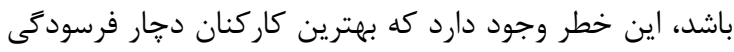

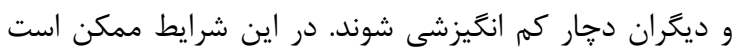

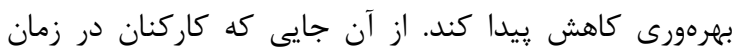

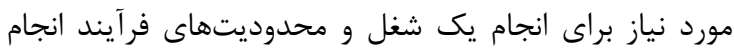

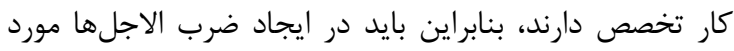
مشورت قرار بخيرند. در زمينه كنترل شغلى نيز بايد كفت زمانى كه كاركنان

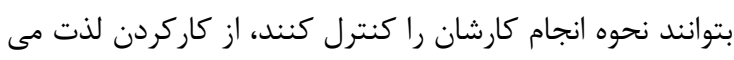

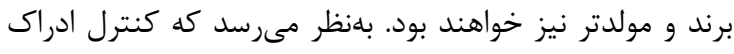

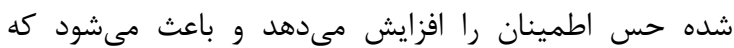
وظايف كمتر استرسزا بهنظر برسند و در اين شرايط انجام

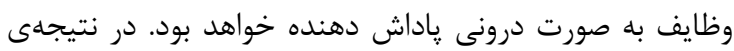

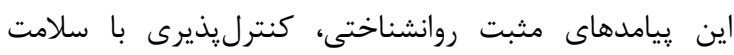

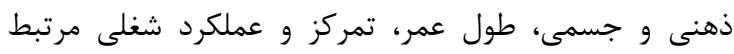

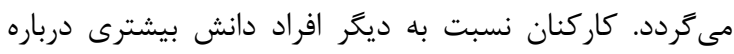

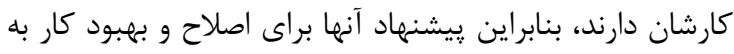
سازمان كارى مولدتر و ايجاد بجرهورى بيشتر منجر مى كر كردد. كارگرى كه فعال و قادر به داشتن آزادى عمل (انجام وظايف

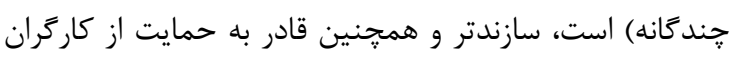

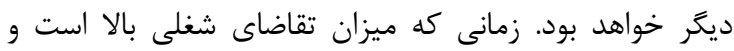

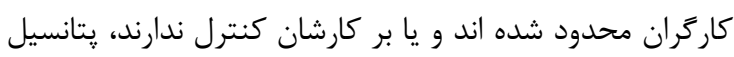

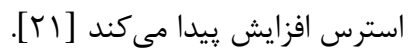

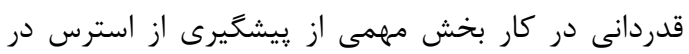

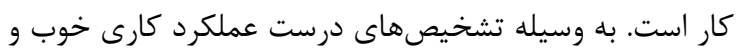

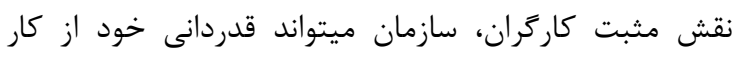

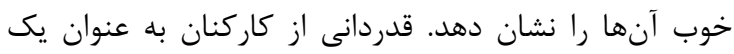

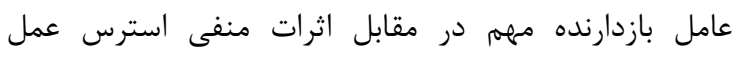

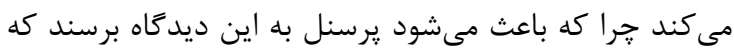

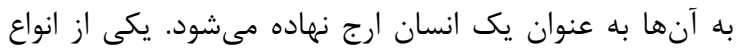

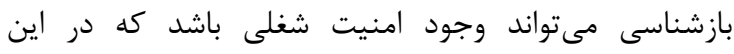

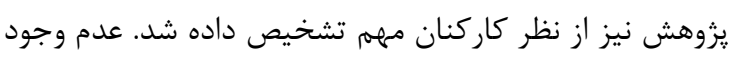

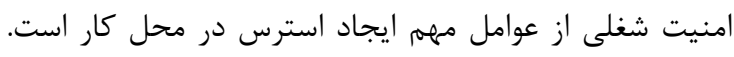

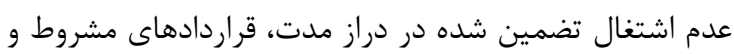

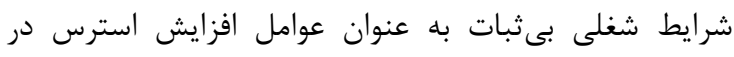

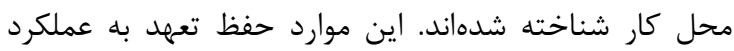

4. Gholami T, Heidari Pahlavian A, Akbarzadeh M, Motamedzade M, Heidari Moghadam R. A structural equation modeling study of job stress and musculoskeletal disorders. Journal of Ergonomics. 2015;3(3):51-64.

5. Hamidi Y, Mortezaei M, Heidari Pahlavian A ,Soltanian AR, Heidari Moghaddam R. The Relationship among Quality of Work Life, Participation and Stress Levels in Health Center Workers. Journal of Ergonomics. 2015;2(4):18-24.

6. Salahian A, Oreizi H, Babamiri M, Asgari A. The predictor factors of burnout syndrome in Isfahan nurses. 2012. 
7. Babamiri M, Zahiri A, Morovati Z, Yousefi Afrashte M, Dehghani Y. Evaluation of Factors Affecting Job Burnout in Employees of Regional Electric Company, Kerman, Iran. Journal of Ergonomics. 2016;3(4):39-48.

8. Heidari Pahlavian A, Gholami T, Heidari Moghaddam R, Akbarzadeh M, Motamedzadeh M. Demand-Control Model and its Relationship with Burnout Syndrome in Nurses. Journal of Fasa University of Medical Sciences. 2015; 5(1):23-35.

9. Creed F, Barsky A. A systematic review of the epidemiology of somatisation disorder and hypochondriasis. Journal of psychosomatic research. 2004;56(4):391-408.

10. Huibers MJ, Beurskens AJ, Van Schayck CP, Bazelmans E, Metsemakers JF, Knottnerus JA, et al. Efficacy of cognitivebehavioural therapy by general practitioners for unexplained fatigue among employees Randomised controlled trial. The British Journal of Psychiatry. 2004;184(3):240-6.

11. Siu OL. Stress management techniques in the workplace. The Routledge Companion to Wellbeing at Work. 2017:284.

12. King BS, Beehr TA. Working with the stress of errors: Error management strategies as coping. International Journal of Stress Management. 2017;24(1):18.

13. Babamiri M, Nisi A, Arshadi N, Shahroie S. Job Stressors as predictors of psychosomatic symptoms. www sjimu medilam ac ir. 2015;23(1):45-55.

14. Babamiri M, Neisi A, Arshadi N, Mehrabizade M, Beshlide Q. Job Stressors and Personality Characteristics as Predictors of Psychosomatic Symptoms at Staff of a Company in Ahvaz. Journal of Psychological Achievements. 2014;4(1):187-208.

15. Babamiri M, Siegrist J, Zemestani M. The Factorial Structure and Psychometric Properties of the Persian EffortReward Imbalance Questionnaire. Safety and Health at Work. 2017.

16. Albini E, Zoni S, Parrinello G, Benedetti L, Lucchini R. An integrated model for the assessment of stress-related risk factors in health care professionals. Industrial health. 2011;49(1):15-23.

17. Kawakami N, Tsutsumi A. The Stress Check Program: a new national policy for monitoring and screening psychosocial stress in the workplace in Japan. Journal of occupational health. 2016;58(1):1-6.

18. O'Brien KE, Beehr TA. Managing employees' occupational stress. Stress and quality of working life: Interpersonal and occupation-based stress. 2016:181-98.

19. Jin P, Yeung AS, Tang T-O, Low R. Identifying teachers at risk in Hong Kong: Psychosomatic symptoms and sources of stress. Journal of psychosomatic research. 2008; 65(4):357-62.

20. Wells JB, Minor KI, Angel E, Matz AK, Amato N. Predictors of job stress among staff in juvenile correctional facilities. Criminal Justice and Behavior. 2009;36(3):245-58.

21. Babamiri M, Nouri N, Abdi Z. Stress prevention at work checkpoint: practical improvement for strees prevention in the workplace. Tehran: Hak; 2016.

22. Rabenu E, Tziner A, Sharoni G. The relationship between work-family conflict, stress, and work attitudes. International Journal of Manpower. 2017;38(8):1143-56.

23. Maslach C, Schaufeli WB, Leiter MP. Job burnout. Annual review of psychology. 2001;52(1):397-422.

24. Kumar R, Töres T, Markeset T. Comparing Psychosocial Factors Associated with Job Stress Among Administrative Staff and Cleaners. Advances in Physical Ergonomics and Human Factors: Springer; 2016. p. 1013-22.

25. Van der Doef M, Verhoeven C. The Job Demand-Control (Support) Model in the Teaching Context. Educator Stress: Springer; 2017. p. 197-222.

26. Lindholm M. Working conditions, psychosocial resources and work stress in nurses and physicians in chief managers' positions. Journal of nursing management. 2006;14(4):300-9. 